\title{
Characterization of particulate matter deposited on urban tree foliage: A landscape analysis approach
}

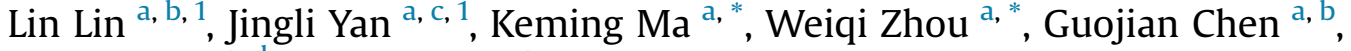 \\ Rongli Tang a, d, Yuxin Zhang ${ }^{a}$ \\ a State Key Laboratory of Urban and Regional Ecology, Research Center for Eco-Environmental Sciences, Chinese Academy of Sciences, Shuangqing Road 18, \\ Haidian District, Beijing 100085, China \\ ${ }^{\mathrm{b}}$ University of Chinese Academy of Sciences, 19 A Yuquan Rd, Shijingshan District, Beijing, 100049, China \\ ${ }^{c}$ Department of Botany and Plant Sciences, University of California, 900 University Ave., Riverside, CA 92521, United States \\ d Chongqing Academy of Agricultural Sciences, Baixin Road 100, Baishiyi Town, Jiulongpo District, Chongqing, China
}

\section{H I G H L I G H T S}

- Object-based method was applied to identify particles of leaf FESEM images.

- A computer-based landscape analysis was applied to leaf surface particles.

- Willow is efficient in dust retention in term of quantity and quality.

- Different PM size fractions show distinct spatial distribution characteristics.

\section{A R T I C L E I N F O}

\section{Article history:}

Received 7 April 2017

Received in revised form 4 August 2017

Accepted 5 September 2017

Available online 6 September 2017

\section{Keywords:}

Air pollution

FESEM

Fragstats

Object-based classification

Spatial characteristic

Urban forestry

\section{G R A P H I C A L A B S T R A C T}

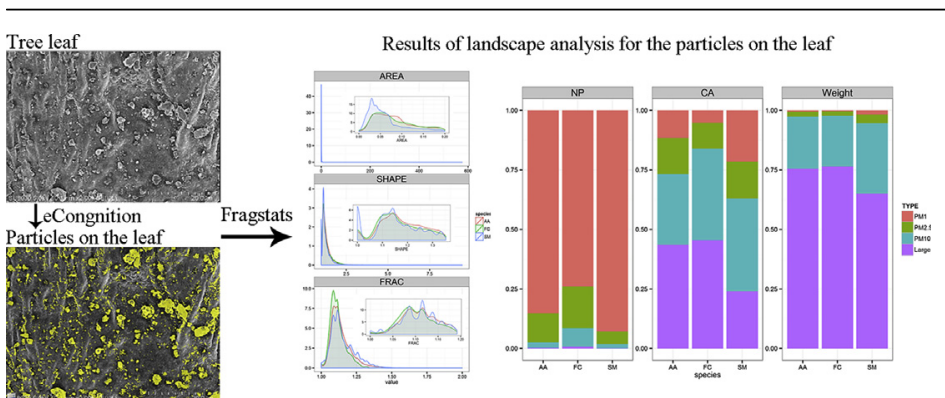

\section{A B S T R A C T}

Plants can mitigate ambient particulate matter by cleaning the air, which is crucial to urban environments. A novel approach was presented to quantitatively characterize particulate matter deposited on urban tree foliage. This approach could accurately quantify the number, size, shape, and spatial distribution of particles with different diameters on leaves. Spatial distribution is represented by proximity, which measures the closeness of particles. We sampled three common broadleaf species and obtained images through field emission scanning electron microscopy. We conducted the object-based method to extract particles from images. We then used Fragstats to analyze the landscape characteristics of these particles in term of selected metrics. Results reveal that Salix matsudana is more efficient than Ailanthus altissima and Fraxinus chinensis in terms of the number and area of particles per unit area and the proportion of fine particulate matter. The shape complexity of the particles increases with their size. Among the three species, S. matsudana and A. altissima particles respectively yield the highest and lowest proximity. $\mathrm{PM}_{1}$ in $\mathrm{A}$. altissima and $\mathrm{PM}_{10}$ in $\mathrm{F}$. chinensis and $\mathrm{S}$. matsudana show the highest proximity, which may influence subsequent particle retention. S. matsudana should be generally

\footnotetext{
* Corresponding authors. State Key Laboratory of Urban and Regional Ecology, Research Center for Eco-Environmental Sciences, Chinese Academy of Sciences, Shuangqing Road 18, Haidian District, Beijing 100085, China.

E-mail addresses: mkm@rcees.ac.cn (K. Ma),wzhou@rcees.ac.cn (W. Zhou).

${ }^{1}$ Lin Lin and Jingli Yan contributed equally to this work.
} 
considered to collect additional small particles. Different species and particle sizes exhibit various proximities, which should be further examined to elucidate the underlying mechanism.

(C) 2017 Published by Elsevier Ltd.

\section{Introduction}

Particulate pollution is a worldwidely environmental problem, and population-weighted ambient $\mathrm{PM}_{2.5}$ concentrations have increased significantly(van Donkelaar et al., 2015). Particulate pollution can modulate global, regional (Buseck and Posfai, 1999; Wang et al., 2014), and local climates (Cao et al., 2016; Rosenfeld, 2000). This phenomenon is also concerned as a severe health risk (Kampa and Castanas, 2008; Nowak et al., 2014) that increases population mortality (Madaniyazi et al., 2015) and premature mortality (Xie et al., 2016). East Asia experiences severe urban particulate matter pollution (Boys et al., 2014), and urban areas, especially megacities, such as Beijing (Guo et al., 2014), are polluted by various sources (Bell et al., 2011). Optically scattering aerosols account for most of the total amount of aerosols in China (Zhang et al., 2012).

Vegetation can provide various ecosystem services, including air purification (Baumgardner et al., 2012; Beckett et al., 1998; Irga et al., 2015). Urban forests can be used as "biotechnology" to ameliorate urban air quality (Nowak, 2006) and it was estimated that, in the US, urban trees removed 214,900 tons PM10 based on data in 1994, providing an applicable way of improving air quality (Nowak et al., 2006). When modelling the functionality of the urban forest, taking the spatial heterogeneity into air pollution removed by urban forest is necessary (Escobedo and Nowak, 2009). A combination of the Weather Research and Forecasting (WRF) model and iTree can be useful in estimating regional pollutant removal by urban forests when field sampled data on trees in an area are not available (Cabaraban et al., 2013). Based on the modelling of tree effects on $\mathrm{PM}_{2.5}$ concentrations and human health in ten U.S. cities, the amount of $\mathrm{PM}_{2.5}$ removed annually by urban trees varied between cities with annual values to human health varying from \$1.1 million to \$60.1 million (Nowak et al., 2013). In country level, the trees in U.S. removed 17.4 million tonnes of air pollutant in 2010 and the human health value was 6.8 billion U.S. dollars (Nowak et al., 2014). On air quality improvement, rural vegetation had greater effects while on human health urban vegetation had greater effects (Hirabayashi and Nowak, 2016).

In the street environment urban plants can affect air quality by means of affecting deposition and dispersion of the pollutants, and consequently the design and choice of vegetation barriers matters (Abhijith et al., 2017; Janhäll, 2015). In addition, the wind direction greatly influences pollutant concentrations of the environment adjacent to the road, depending on the relative location of road and the vegetation according to the wind direction, and the air pollutant concentrations decline to background values between 115 and $570 \mathrm{~m}$ or $160-570 \mathrm{~m}$ according to different normalization methods (Karner et al., 2010). The combination of barrier and mature trees brought about consistently lower pollutant concentrations (Baldauf et al., 2008). Furthermore, wide vegetation barriers with dense leaf and vegetation-solid barrier combinations are two types of design that effectively reduce downwind particle concentration (Tong et al., 2016).

To identify effective particle retention species, we should quantify particles on plant leaves by using various techniques. For instance, microscopic observation is commonly used to determine the amount of particles on leaves (Sgrigna et al., 2016; Song et al.,
2015). Compared with water wash method, microscopy can quantify particles with original diameters (Yan et al., 2016a). Compared with the wind tunnel method, microscopy can identify particle deposition in actual environments, where particles yield various diameters. Microscopy can also obtain species-specific information regarding particle retention effect; conversely, the model method (Tiwary et al., 2009) can estimate the large-scale removal of particulate matter by vegetation, and some models can consider spatial variation (Hirabayashi et al., 2012). Compared with the spectrum method (Yan et al., 2015), microscopy can reveal the size distribution and shape information of particles and may indicate the source of particles (StoffynEgli et al., 1997).

Microscopy has been performed to quantify the number and shape of particles retained on tree leaves (Deljanin et al., 2014; Manisha et al., 2016). Using an automatic mapping approach (Yan et al., 2016b), we can quantitatively characterize the spatial distribution of particles on leaves. This parameter can potentially indicate the particle deposition process on leaf surfaces and provide new insights into particle retention and its characteristics. However, the spatial distribution pattern of leaf particles has yet to be quantified. Landscape metrics showing landscape patterns are calculated by using the landscape analysis software Fragstats. These metrics include three levels: landscape, class, and patch. Landscape level metrics can quantify the overall condition of the particles (i.e. number density, leaf area percentage covered by particles); class level metrics can quantify characteristics of particles from different fractions including spatial patterns that can quantify the spatial

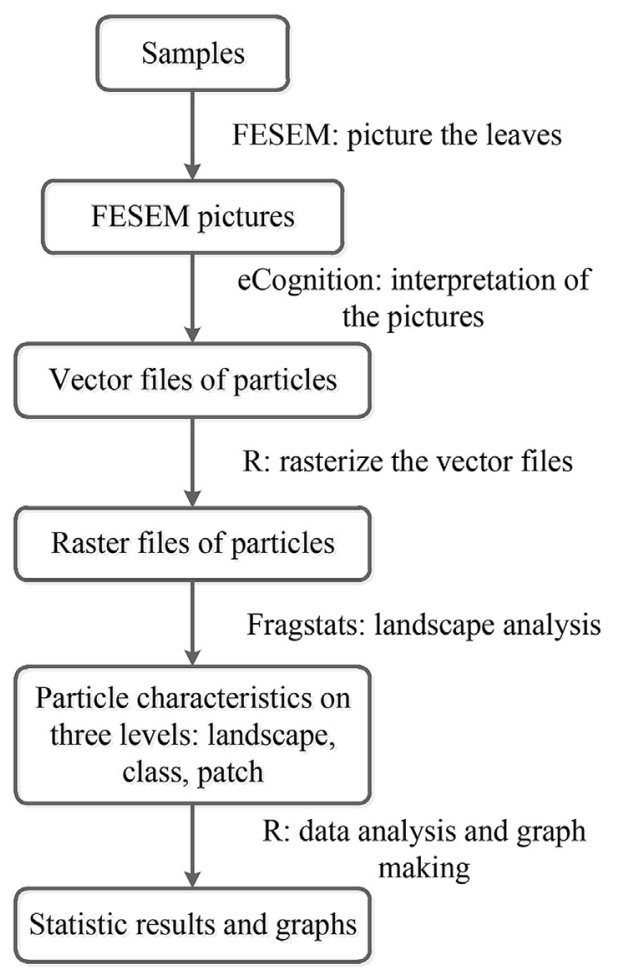

Fig. 1. Flow chart for data process. 
distribution of leaf particles; patch level metrics can quantify characteristics of individual particles (area and shape). Using a landscape framework, we can quantify and summarize the size, shape, and spatial pattern of leaf particles. However, this method has been rarely used in studies. Therefore, this study aimed to (1) apply the landscape concept and method for the quantification of leaf particle characteristics; (2) determine the differences among three common broadleaf species in terms of the number of particles, leaf area covered by these particles, and particle weight; and (3) compare the characteristics of particles with different diameter intervals in terms of their number, area, and spatial distribution in common broadleaf species.

\section{Methods}

The data process from sampling to landscape analysis is summarized in the flow chart (Fig. 1). The boxes represent the material or the data to be processed. The text beside the arrows denotes the equipment or software used and the processes conducted.

\subsection{Sampling}

We collected the samples from sites near the fifth ring road in the Olympic Forest Park in Beijing on May 22, 2015, five days after the latest precipitation on May 17, 2015. We used high-reach scissors to cut leaves from three common broadleaf species: ailanthus (Ailanthus altissima (Mill.) Swingle, AA), ash (Fraxinus chinensis Roxb., FC), and willow (Salix matsudana, SM). Leaves facing the road were chosen to better represent the particulate matter on the leaf of which the road dust may be an important source. The distance from sample trees of AA, FC and SM to the nearest road was 16,14 and $13 \mathrm{~m}$ respectively. To avoid differences, the sampled trees were all at the same site near each other (Fig. 2). The three trees we chose had similar distance to the road, sunlight, wind condition and individual size. The prevailing wind direction was Northwest in spring in Beijing (Sun et al., 2015) and the sampled trees were located south of the road.

We chose one healthy tree for each species and randomly cut leaves facing the road at $3 \mathrm{~m}$ height. We chose the three species because they are common in Beijing and have distinct leaf characteristics. The leaves of AA have microgrooves but do not have hair; the leaves of FC have coarse texture but do not have hair; and the leaves of SM have sparse hair and dense stoma. Leaves were carefully put into paper envelopes to avoid further contamination and particles falling, and then to the lab for further analysis.
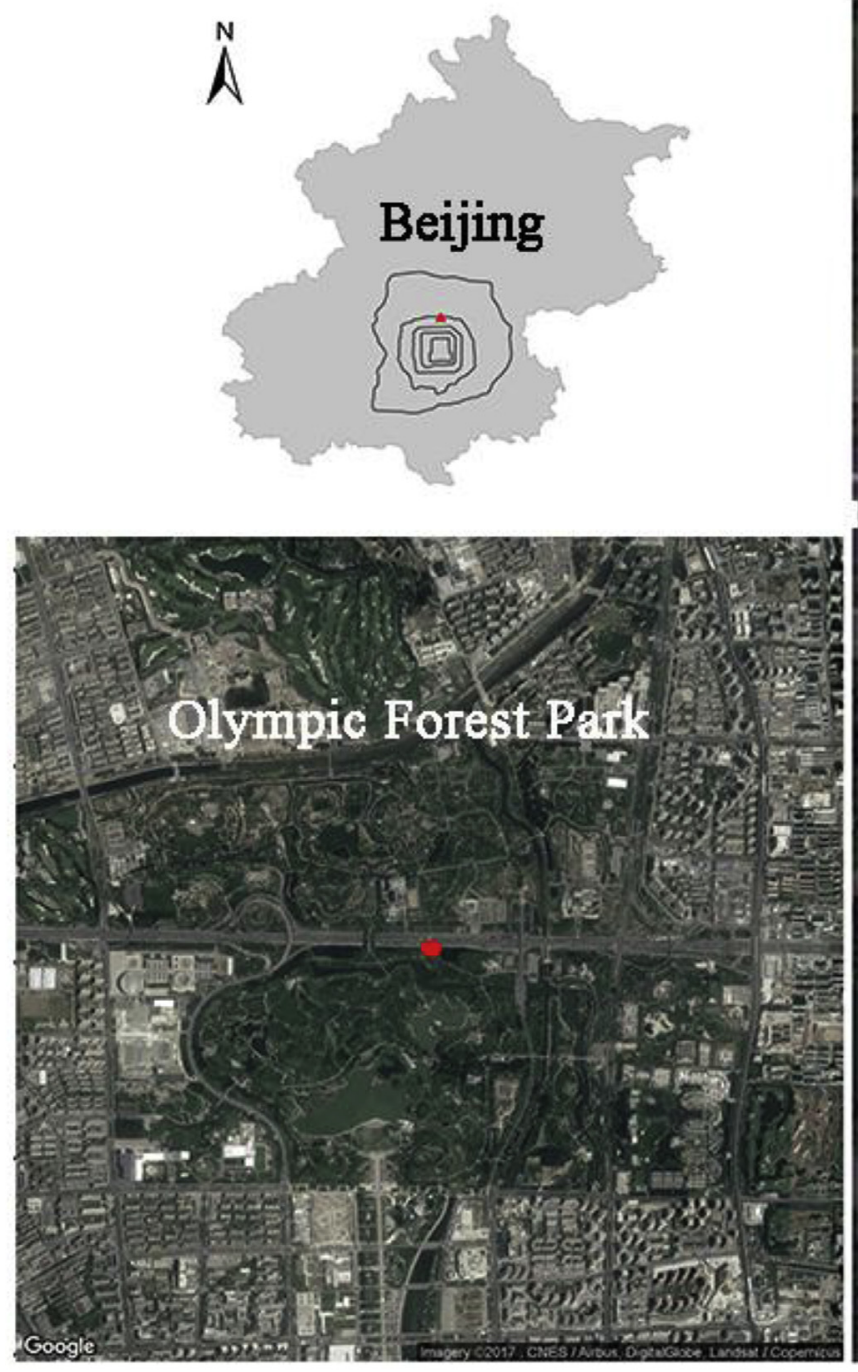

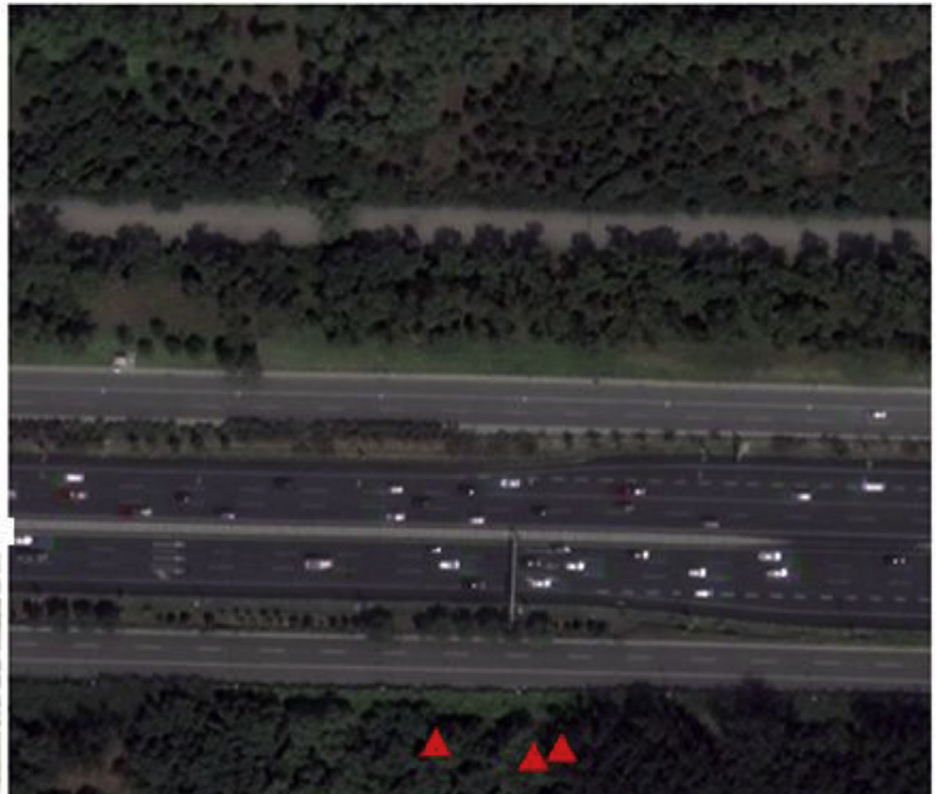

Sample trees

Fig. 2. The sampling location for three species, located in the Olympic Forest Park in Beijing. 


\section{a: Examples of classification results-AA}

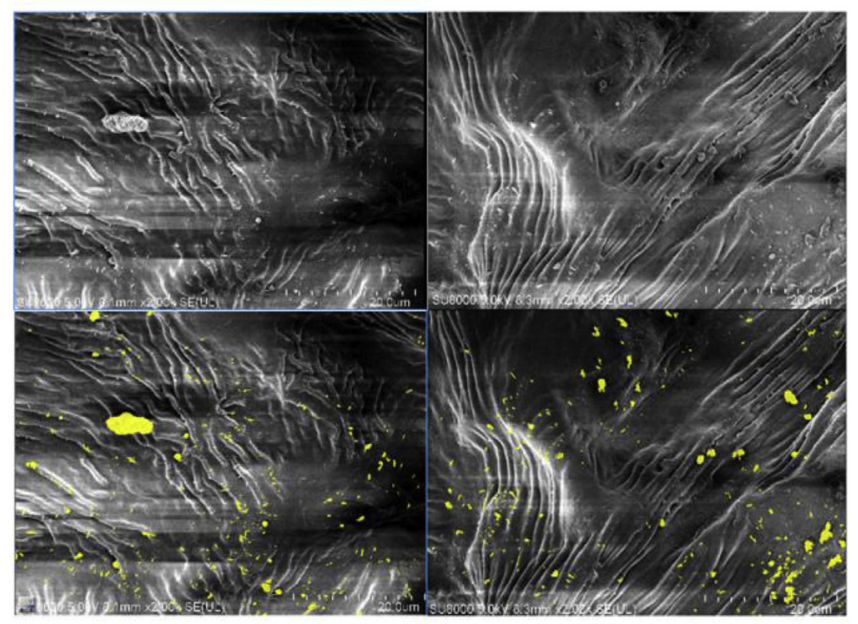

b: Examples of classification results-FC

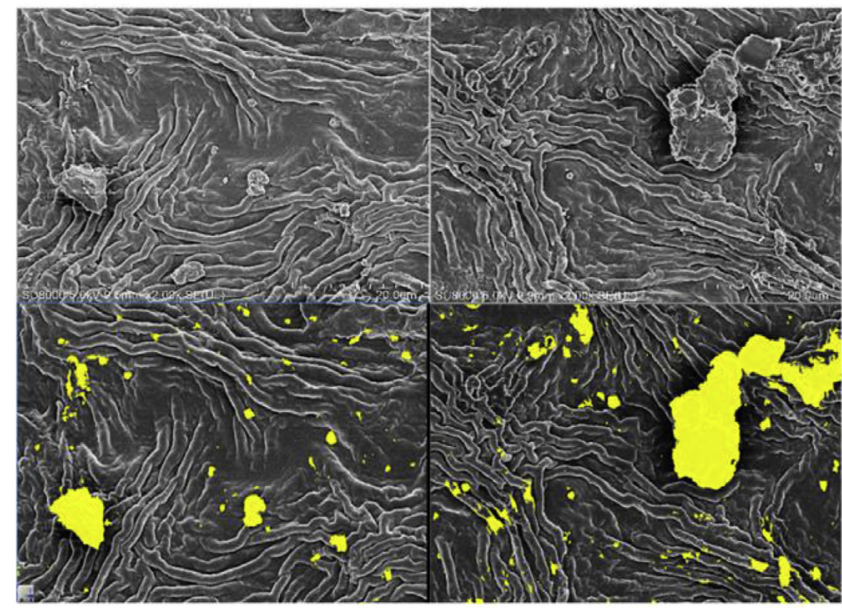

c: Examples of classification results-SM

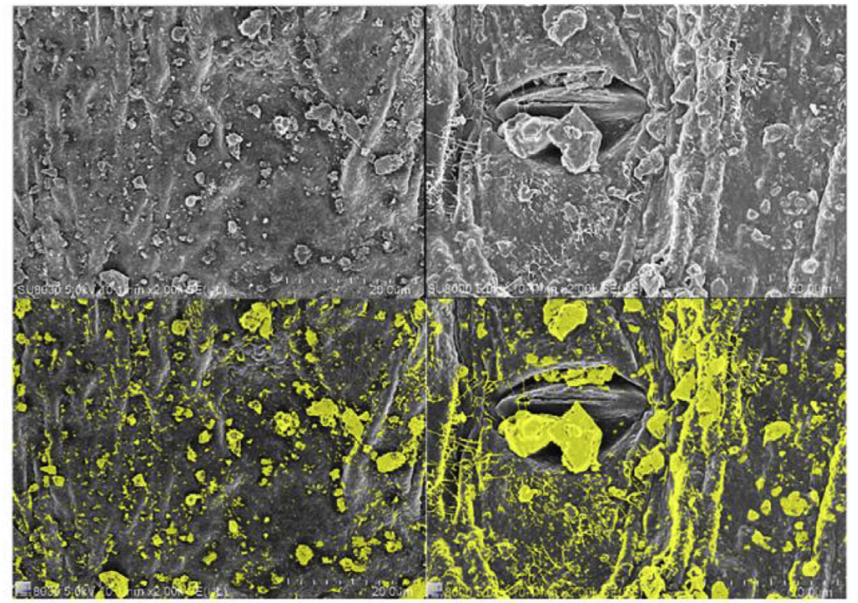

Fig. 3. Examples of classification results. AA: ailanthus (Ailanthus altissima (Mill.) Swingle); FC: ash (Fraxinus chinensis Roxb.); SM: willow (Salix matsudana Koidz.). The magnification of the these pictures are 2000. The yellow parts represent the particles recognized by software eCongition. (For interpretation of the references to colour in this figure legend, the reader is referred to the web version of this article.)

\subsection{Scanning electron microscopy}

We randomly chose fifteen healthy leaves to represent those three species, five leaves for each species. For each leaf, one square sample of approximately $1 \mathrm{~cm} \times 1 \mathrm{~cm}$ was cut out from the middle part of the leaf avoiding the veins. The samples were coated with gold to increase productivity. After the pretreatment, we photographed the samples under a field emission scanning electron microscope (FESEM, Hitachi SU-8020) at an accelerating voltage of 3-5 kV at magnification of 2000; seventy-five images were taken, five images for each sample. The pixel amount for each picture was $1,228,800$, and each pixel was $0.05 \mu \mathrm{m}$ in size. The area of one pixel was $25 \times 10^{-4} \mu \mathrm{m}^{2}$, and the total area for one image was $3072 \mu \mathrm{m}^{2}$.

\subsection{Object-based classifications}

We used the object-based classification method to extract the particles from the SEM micrographs automatically (Yan et al., 2016b). These micrographs were imported into eCognition Developer $^{\mathrm{TM}}$ software. The eCognition Developer TM software is a widely used remote sensing software which can be used to conduct the classification for remote sensed images. The object-based method embedded in the eCongnition is effective in classification, overcoming some of the shortages of pixel-based classification methods(Yu et al., 2006). Initially, the optimal segmentation scale, color, and shape parameter were set to conduct a multi-resolution segmentation algorithm We then applied the ruleset-based classification to the entire micrograph for particle matter identification. Finally, we merged the adjacent image objects of the same class to get the particles and, the result was exported as vector files for further analysis. Examples of the classification are shown in Fig. 3.

\subsection{Landscape analysis}

The vector files were imported into R. According to the width and length of particles extracted by eCognition Developer ${ }^{\mathrm{TM}}$ software, the diameter was the average of width and length. Based on the geometrical diameter, the particles were divided into four classes: $\mathrm{PM}_{1}$ (diameter $\left.\leq 1 \mu \mathrm{m}\right), \mathrm{PM}_{2.5}(1 \mu \mathrm{m}<$ diameter $\leq 2.5 \mu \mathrm{m})$, $\mathrm{PM}_{10}(2.5 \mu \mathrm{m}<$ diameter $\leq 10 \mu \mathrm{m})$, Large (diameter $\left.>10 \mu \mathrm{m}\right)$.

We rasterized the vector files using the raster function and exported the results as. tiff by using the writeRaster function in $\mathrm{R}$ package raster (Hijmans, 2015) in the $\mathrm{R}$ base version 3.1.2 (R Core Team, 2014), resulting in 49931 particles. To calculate the landscape metrics, the rasterized files were imported into Fragstats v4.2.1(McGarigal et al., 2012). Metrics representing the particle number, the particle area, the shape characteristic of particles, and proximity of class particles were chosen from the metrics provided by Fragstats (Table 1 ).

There are several principles in selecting the metrics. First, core area metrics were not chosen because they need the definition of the width of the edge whereas there was neither practical meaning for leaf particle nor standard for edge width. Second, contrast metrics which describe the degree of dissimilarity of adjacent patches (patches share part of their edges) were not chosen because adjacent particles were merged into one particle. Similarly, all metrics based on adjacent matrix were not chosen such as contag, iji, clumpy and PLADJ. Third, the aggregation, subdivision and isolation metrics were not chosen because they are pixel based metrics describing both size and shape which was of irrelevant meaning for leaf particles. Fourth, metrics representing the fragmentation were not chosen (such as split and cohension), because they have no explicit meaning for leaf particles. Some measurement unit transformations from SEM pictures to real data were made to accurately reflect the landscape metrics based on the 
Table 1

Description of landscape metrics transformed and evaluated.

\begin{tabular}{|c|c|c|c|c|}
\hline $\begin{array}{l}\text { Landscape metrics } \\
\text { (full name) }\end{array}$ & Level & Description in landscape ecology & Transformation & $\begin{array}{l}\text { Meaning in particles on } \\
\text { the leaf }\end{array}$ \\
\hline NP(Number of Patch) & $\begin{array}{l}\text { Landscape, } \\
\text { Class }\end{array}$ & $\begin{array}{l}\text { NP equals the number of patches of the landscape and corresponding patch } \\
\text { type (class). }\end{array}$ & $\div 3072 \times\left(10^{6}\right)$ & $\begin{array}{l}\text { Number of particles per } \\
\text { unit } \mathrm{mm}^{2}\end{array}$ \\
\hline CA(Class Area) & Class & $\begin{array}{l}\text { CA equals the sum of the areas }\left(\mathrm{m}^{2}\right) \text { of all patches of the corresponding patch } \\
\text { type divided by } 10,000 \text { (to convert to hectares). It is a measure of landscape } \\
\text { composition. }\end{array}$ & $\times 10000 \times 0.05 \times 0.05 \div 3072$ & $\begin{array}{l}\text { Propotion of leaf area } \\
\text { covered by the class } \\
\text { particles }\end{array}$ \\
\hline TA(Total Area) & Landscape & $\begin{array}{l}\text { TA equals the total area }(\mathrm{m} 2) \text { of the landscape, divided by } 10,000 \text { (to convert to } \\
\text { hectares). Note, total landscape area }(\mathrm{A}) \text { includes any internal }\end{array}$ & $\times 10000 \times 0.05 \times 0.05 \div 3072$ & $\begin{array}{l}\text { Propotion of leaf area } \\
\text { covered by all the } \\
\text { particles }\end{array}$ \\
\hline Area_MN, AREA & Class, Patch & $\begin{array}{l}\text { AREA equals the area }\left(\mathrm{m}^{2}\right) \text { of the patch, divided by } 10,000 \text { (to convert to } \\
\text { hectares). }\end{array}$ & $\times 10000 \times 0.05 \times 0.05$ & $\begin{array}{l}\text { The area of the particles } \\
\left(\mu \mathrm{m}^{2}\right)\end{array}$ \\
\hline SHAPE_MN, SHAPE & Class, Patch & $\begin{array}{l}\text { SHAPE equals patch perimeter }(\mathrm{m}) \text { divided by the square root of patch area } \\
\left(\mathrm{m}^{2}\right) \text {, adjusted by a constant to adjust for a square standard. }\end{array}$ & none & Shape index of particles \\
\hline $\begin{array}{l}\text { FRAC_MN(Fractal } \\
\text { Dimension Index), } \\
\text { FRAC }\end{array}$ & Class, Patch & $\begin{array}{l}\text { FRAC equals } 2 \text { times the logarithm of patch perimeter }(\mathrm{m}) \text { divided by the } \\
\text { logarithm of patch area }\left(\mathrm{m}^{2}\right) \text {; the perimeter is adjusted to correct for the raster } \\
\text { bias in perimeter. }\end{array}$ & none & $\begin{array}{l}\text { Fractal dimension } \\
\text { index of particles }\end{array}$ \\
\hline $\begin{array}{l}\text { PROX_MN(proximity } \\
\text { Index) }\end{array}$ & Class & $\begin{array}{l}\text { PROX equals the sum of patch area }\left(\mathrm{m}^{2}\right) \text { divided by the nearest edge-to-edge } \\
\text { distance squared }\left(\mathrm{m}^{2}\right) \text { between the patch and the focal patch of all patches of } \\
\text { the corresponding patch type whose edges are within a specified distance }(\mathrm{m}) \\
\text { of the focal patch. Note, when the search buffer extends beyond the landscape } \\
\text { boundary, only patches contained within the landscape are considered in the } \\
\text { computations. In addition, note that the edge-to-edge distances are from cell } \\
\text { center to cell center. }\end{array}$ & none & $\begin{array}{l}\text { proximity index of } \\
\text { particles }\end{array}$ \\
\hline
\end{tabular}

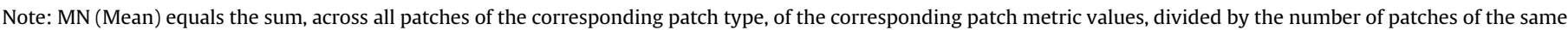
type. $\mathrm{MN}$ is given in the same units as the corresponding patch metric.
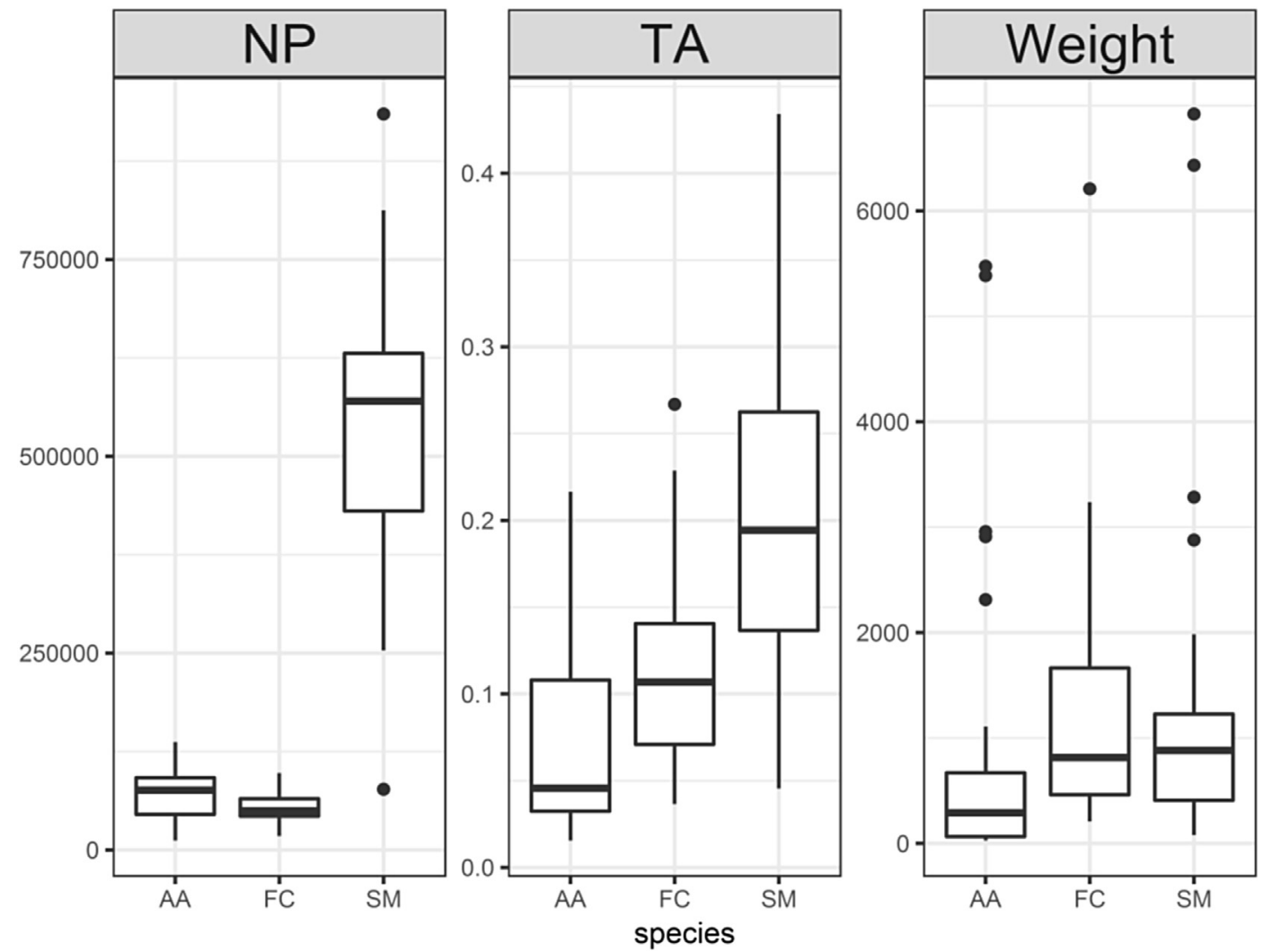

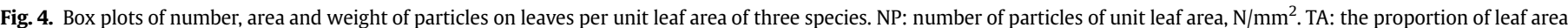

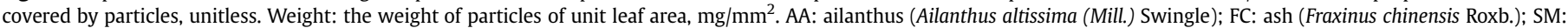
willow (Salix matsudana Koidz.).

information in 2.2, and the details of the transformation process are in Table 1.

The particle weight was calculated based on the diameters. First, the particle was assumed to be spherical, and the diameter was divided by two to get the radius. Second the particle volume was calculated using the radius. Third, the weight was the product of the volume and density $2 \mathrm{~g} / \mathrm{cm}^{3}$ (Zhang and He, 2014). Graphs for comparing those metrics were drawn using $\mathrm{R}$ package ggplot2 (Wickham, 2009). 

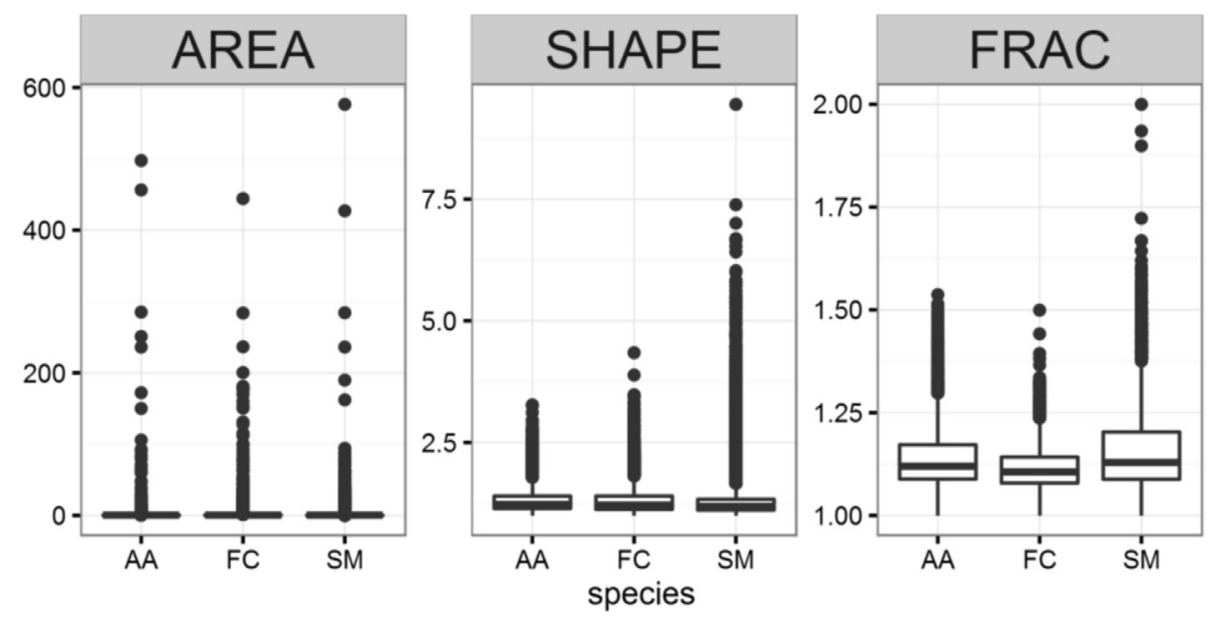

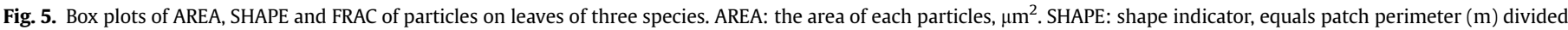

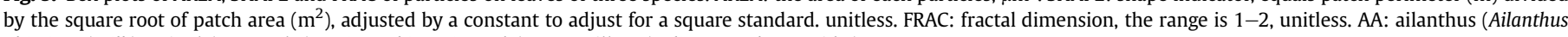
altissima (Mill.) Swingle); FC: ash (Fraxinus chinensis Roxb.); SM: willow (Salix matsudana Koidz.).

\section{Results}

\subsection{Amount, area, and weight of particles}

As shown in Fig. 4, the SM accumulated the most particles in terms of amount, area and weight per unit leaf surface. The median value of the number of patch (NP) of SM $\left(569987 / \mathrm{mm}^{2}\right)$ was approximately 10 times that of $\mathrm{FC}\left(49805 / \mathrm{mm}^{2}\right)$ and 8 times of AA $\left(75846 / \mathrm{mm}^{2}\right)$. Moreover, the NP variation of SM is the largest, whereas that of FC is the smallest. The biggest particles appeared in SM.

The medians of total area (TA) for AA, FC, and SM were $4.6 \%$, $10.7 \%$, and $19.4 \%$, respectively; therefore, SM had the highest leaf coverage of particles among the three species, and AA had the lowest. The variation of TA of SM was the highest, and the variation of TA of FC was the lowest.

The median weight for AA, FC, and SM were 189, 530, and $573 \mathrm{ng} / \mathrm{mm}^{2}$, respectively. SM had the highest particle weight per unit leaf area and AA had the lowest. The picture that the particles' weight was the most showed up in SM. The variation of weight of SM was the highest, whereas that of FC was the lowest.

\subsection{The characteristics of particle area and shape indexes}

\subsubsection{Particle AREA, SHAPE, and FRAC}

As shown in Fig. 5, the median value of area of each particle (AREA) for SM was $0.0575 \mu \mathrm{m}^{2}$, which is the smallest among the three species; moreover, it was approximately half that of AA $\left(0.1025 \mu \mathrm{m}^{2}\right)$ and one-third that of FC $\left(0.1725 \mu \mathrm{m}^{2}\right)$. Meanwhile, the variation of the AREA of FC was the highest (the interquartile range was 0.5750 ), whereas that of SM was the smallest (the interquartile range was 0.0875 ).

As for the shape, the SHAPE index median values of the three species were close, ranging from 1.182 (SM) to 1.231 (AA); therefore, most of the particles were similar in shape complexity. The SHAPE of FC particles (the interquartile range was 0.2750 ) had a higher variation than AA (0.2571) and SM (0.2220).

Another shape indicator was FRAC. The FRAC median values of the three species were close, ranging from 1.106 (FC) to 1.129 (SM). Moreover, the FRAC of SM particles (the interquartile range was $0.1150)$ had a higher variation than FC (0.0633) and AA (0.0834).

\subsubsection{Distribution of particle AREA, SHAPE, and FRAC}

As shown in Fig. 6, regarding particle size, the SM distribution curve is sharp, indicating that the particle area distribution was centralized; moreover, the value peaked at approximately $0.03 \mu \mathrm{m}^{2}$. In contrast, the shapes of AA and FC were similar and had moderately high value intervals from 0.04 to 0.09 and $0.04-0.07$, respectively.

Regarding the SHAPE of particles, valleys occurred at approximately 1.02 for all the three species. The first peaks appeared at approximately 1, with SM having the highest peak; therefore, the particle proportion with SHAPE value surrounding 1 was higher than those of AA and FC. Moreover, among the three species, a moderately high value interval occurred: $1.1-1.2$, demonstrating that particles in that range were abundant for all three species.

The FRAC curves were similar, suggesting that the FRAC values of the particles of the three species coincided. The high value interval was $1.00-1.20$, with two peaks occurring for each species.

\subsection{Class level characteristics based on landscape analysis}

\subsubsection{Characteristics of the particles at four class levels}

As illustrated in Fig. 7, regarding CA characteristic, AA and FC displayed similar trends: the median values of class particles monotonically increased with the particle diameter. Large particles had high median values (3\% and 5.8\% for AA and FC, respectively) and $\mathrm{PM}_{1}$ had low median values $(0.9 \%$ and $0.6 \%$ for $\mathrm{AA}$ and $\mathrm{FC}$, respectively). For $\mathrm{SM}$, however, the CA median values of $\mathrm{PM}_{10}(6.6 \%)$ was the highest among the four classes, followed by $\mathrm{PM}_{10}$, Large (5.2\%), $\mathrm{PM}_{1}$ (4.5\%), and $\mathrm{PM}_{2.5}$ (2.7\%). Regarding NP, the median value decreased as the particle diameter increased. $\mathrm{PM}_{1}$ had high median values: 57943, 38086, and 543294 for AA, FC, and SM, respectively. Large particles had low median values: 325,325 , and 1320 for AA, FC, and SM, respectively. The number of $\mathrm{PM}_{1}$ was 100-400 times that of Large particles. As for AREA_MN, the median value SM was the lowest among the four classes, whereas that of FC was the highest. SM and AA have close median values of AREA_MN of $\mathrm{PM}_{10}$. The highest difference occurred in Large class, FC $\left(131.05 \mu \mathrm{m}^{2}\right)$ tripled SM $\left(40.36 \mu \mathrm{m}^{2}\right)$. Except for AA, the shape complexity increased with the class level. Among the four classes, $\mathrm{PM}_{1}$ had the simplest shape throughout three species; AA had particles with more complicated shapes than SM and FC. In classes $\mathrm{PM}_{2.5}, \mathrm{PM}_{10}$, and Large, SM generally had complicated particles, whereas AA and FC had relatively simple particles. Regarding 
Weight, that of corresponding class particles increased as the class level increased. For the Large class, FC had high weight. For $\mathrm{PM}_{1}$, $\mathrm{PM}_{2.5}$, and $\mathrm{PM}_{10}$, SM had the highest weight.

\subsubsection{Proportion of four class particles in NP, CA, and weight}

As shown in Fig. 8, in terms of NP, $\mathrm{PM}_{1}$ was the predominant class. Overall, $\mathrm{PM}_{1}$ accounted for 70\%-95\%; $\mathrm{PM}_{2.5}$ accounted for $5 \%-20 \% \mathrm{PM}_{10}$ accounted for $1.5 \%-8 \%$, and Large accounted for $0.1 \%-0.8 \%$. In terms of $\mathrm{CA}, \mathrm{PM}_{10}$ and Large were the predominant classes. In general, $\mathrm{PM}_{1}$ accounted for $5 \%-25 \%, \mathrm{PM}_{2.5}$ accounted for $10 \%-16 \%, \mathrm{PM}_{10}$ accounted for $30 \%-40 \%$, and Large accounted for $20 \%-45 \%$. In terms of Weight, Large was the predominant class. Generally, $\mathrm{PM}_{1}$ accounted for $0.3 \%-2 \%, \mathrm{PM}_{2.5}$ accounted for $1.5 \%-$ $4 \%, \mathrm{PM}_{10}$ accounted for $20 \%-30 \%$, and Large accounted for $65 \%-$ $75 \%$.

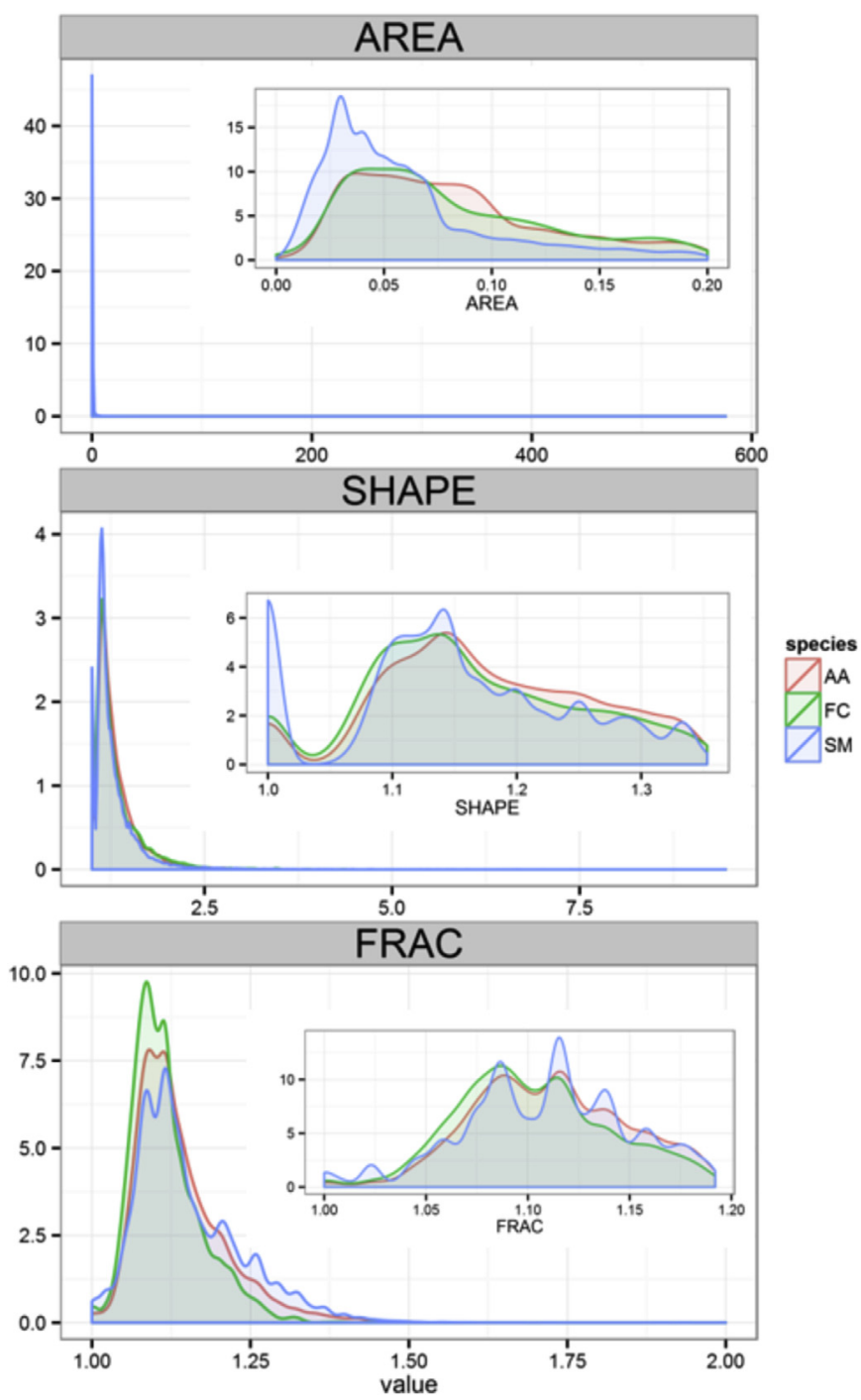

Fig. 6. The PM AREA, SHAPE and FRAC distributions. The small pictures inside the big ones were drawn from subset data of the big ones: data smaller than the third quantile was contained to show the details of the distributions. AREA: the area of each particles, $\mu \mathrm{m}^{2}$. SHAPE: shape indicator, equals patch perimeter $(\mathrm{m})$ divided by the square root of patch area $\left(\mathrm{m}^{2}\right)$, adjusted by a constant to adjust for a square standard. unitless. FRAC: fractal dimension, the range is $1-2$, unitless. AA: ailanthus (Ailanthus altissima (Mill.) Swingle); FC: ash (Fraxinus chinensis Roxb.); SM: willow (Salix matsudana Koidz.).

\subsubsection{Characteristics particulate matter spatial distribution on leaves}

As shown in Fig. 9, the PROX of $\mathrm{PM}_{1}$ of $\mathrm{AA}$ and FC increased when the searching radius reached $1 \mu \mathrm{m}$; whereas that of SM remained high even at a searching radius was $0.5 \mu \mathrm{m}$, and increased as the searching radius elevated. The PROX of $\mathrm{PM}_{2.5}$ of $\mathrm{AA}, \mathrm{FC}$, and SM increased with searching radii of 5,5 , and $1 \mu \mathrm{m}$, respectively. The PROX of $\mathrm{PM}_{10}$ of $\mathrm{AA}, \mathrm{FC}$, and SM increased at 10,5 , and $1 \mu \mathrm{m}$, respectively. Moreover, the PROX of Large of AA was not high under the seven searching radii. The PROX of Large of FC and SM increased at searching radii of 20 and $5 \mu \mathrm{m}$, respectively.

PM of different classes have different proximity characteristics. In general, Large had the lowest proximity. For AA, under all the seven searching radii, the proximity of the class particles decreased as the particle class levels rose. For FC, when the search radius was higher than $5 \mu \mathrm{m}$, from $\mathrm{PM}_{1}, \mathrm{PM}_{2.5}$, and $\mathrm{PM}_{10}$, the proximity rose. For SM, in general, the $\mathrm{PM}_{10}$ had the highest proximity, followed by $\mathrm{PM}_{1}$ and $\mathrm{PM}_{2.5}$.

\section{Discussion}

\subsection{Size and shape distribution}

The leaf surface particles were quantified and described synthetically from four aspects: number, size, shape, and spatial position. SM is efficient in accumulating particles, judging from number, mass, and size distribution; this might be because of the trichrome (Beckett et al., 2000a; Räsänen et al., 2013). Moreover, the leaf grooves have a coarse surface that can facilitate particle deposition on the leaf (Beckett et al., 2000b; Liang et al., 2016).

\subsubsection{Weight and size distribution both embody the air cleaning ability of vegetation}

Small particles, especially fine and ultrafine particles, can be harmful. Small particles are difficult to clear away (Pui et al., 2014). Moreover, fine particles have a relatively high surface area that could absorb toxic materials and increase toxicity (Kelly and Fussell, 2012).

Besides the toxicity, fine particles can reach deep to the respiratory system (Sierra-Vargas and Teran, 2012), thereby causing severe pulmonary conditions (Makkonen et al., 2010; Oberdörster, 2000). Particle number concentrations are correlated with airway inflammation and lung injury (Strak et al., 2012). The $\mathrm{PM}_{1}$ and $\mathrm{PM}_{2.5}$ account for most of the total particle number; however, they account for only a tiny proportion of the total weight. Consequently, evaluating the value of PM cleaning of vegetation using weight might be biased. For example, AA has less weight than FC, but the $\mathrm{PM}_{1}$ proportion was higher. Therefore, based on mass and size distribution, AA is probably a more efficient species than FC.

\subsubsection{Estimation the element source appointment of the particles}

Shape distribution combined with size distribution can be used to estimate the element of particles and facilitate source appointment of the particles. Chemical characteristics of the particles may be inferred by size distribution because differences in size fractions are caused by different components (Grantz et al., 2003). Obtaining the diameter of each particle enables investigation of the sources, the elements contains, and pollutant levels of the particles on the leaf. For example, particles greater than $1 \mu \mathrm{m}$ are mostly generated from natural sources and those less than $1 \mu \mathrm{m}$ are mostly from human activities (Makkonen et al., 2010).

From the ecosystem perspective, particle-polluted leaves could be a source of non-point pollution for urban ecosystems during precipitation (Feng et al., 2001), which is critical in the pollutant transfer from the air to soil and affects biogeochemical cycling 

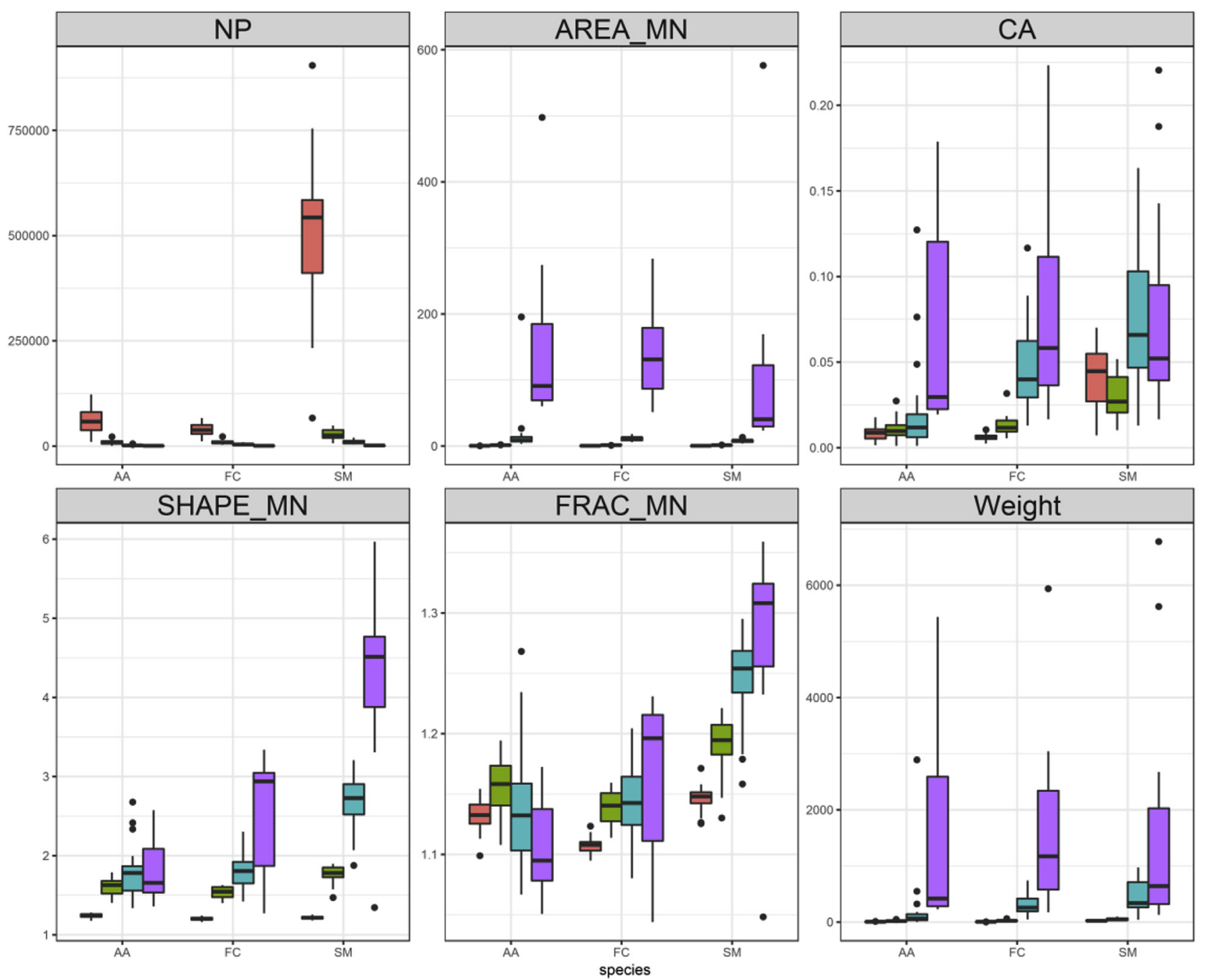

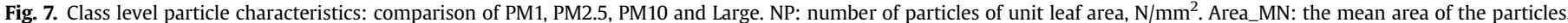

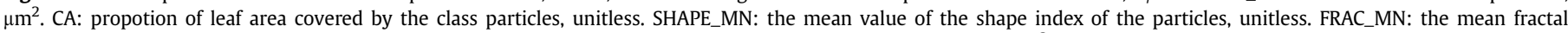

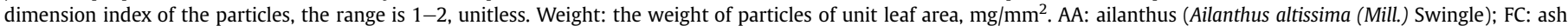
(Fraxinus chinensis Roxb.); SM: willow (Salix matsudana Koidz.).

(Fowler et al., 2009). The results of this study will help high temporal and spatial resolution monitoring (Sgrigna et al., 2016; Zampieri et al., 2013).

\subsection{Class level characteristics}

Large particles, on average, had relatively complicated shapes, with $\mathrm{PM}_{1}$ having the simplest shape. This phenomenon might be because $\mathrm{PM}_{1}$ has mostly anthropogenic sources, such as high temperature combustion (Akram et al., 2014). Moreover, the mean area of SM class particles was the lowest across the four classes and three species, showing that SM probably prefers small particles. Regarding the proportion of particles from different fractions, in general, ultrafine and fine particles are dominant in number, which is consistent with previous studies (Cao et al., 2011; Song et al., 2015). This may be caused by the composition of atmospheric particulate matter: the number concentrations of ultrafine and fine particles are larger than coarse particles. $\mathrm{PM}_{10}$ and Large were dominant in area cover percentage. Large were dominate in weight.
Large particles contained most of the weight (65\%-75\%), however they accounted for less than $1 \%$ in total. Moreover, $\mathrm{PM}_{1}$ accounted for the highest number (70\%-95\%), however, they accounted for less than $2 \%$ in weight.

\subsection{Proximity}

Patterns reflect a specific process. Different species have various canopy and leaf characteristics that may confer distinct spatial characteristics. Moreover, particle proximity is not necessarily congruent with the number of particles. For example, the proximity of $\mathrm{PM}_{10}$ of $\mathrm{FC}$ was higher than that of $\mathrm{PM}_{1}$. Moreover, except for large particles, no determinate relationship exists between the proximity and size of particles. The thick trichomes can maintain a stabilized air layer thus bring about selectively deposition of small particles $(<=1 \mu \mathrm{m})$ (Martell, 1974). Similarly, from the particulate matter deposition dynamic perspective, particles already deposited on the leaf surface may affect subsequent particle deposition. Particles in different classes combined with different leaf surface 

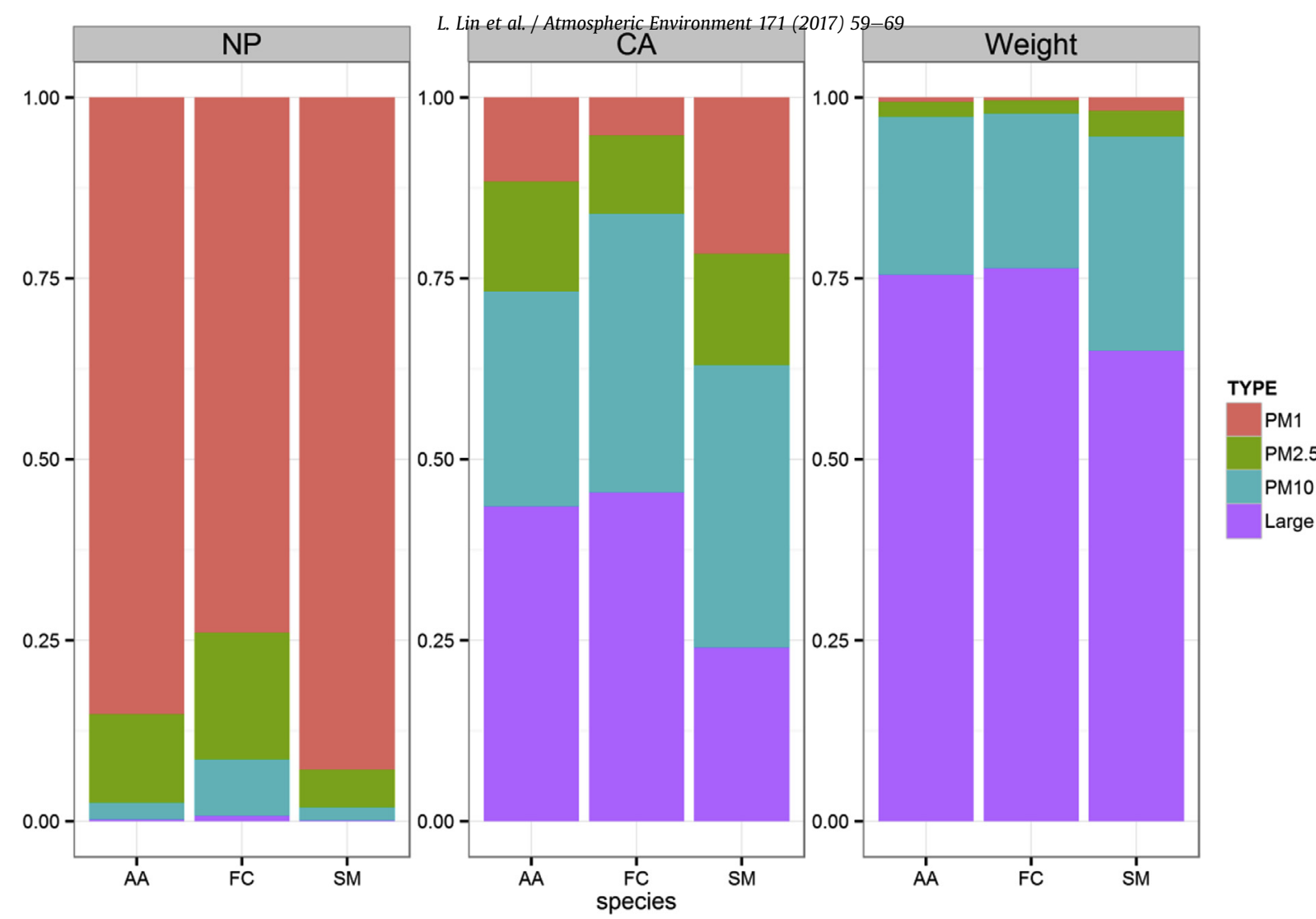

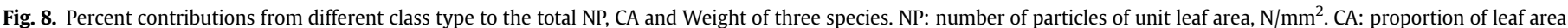

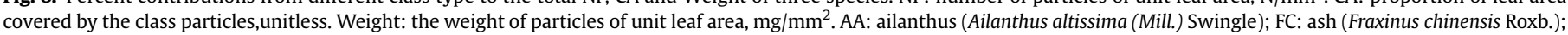
SM: willow (Salix matsudana Koidz.).

structures may play different roles in fixing of new particles. The particles on the leaf may proceed or resist new particles around them. Further studies should be conducted to explore the effects of spatial pattern on particle deposition.

\subsection{Limitations and recommendations for future studies}

This study has several limitations thereby are needed to be clarified by future studies. First, more tree level individuals should be sampled in various environments: both near a source like these samples and perhaps in more regional areas where the particulate loading is more likely similar and not influenced by a particular source and location like in our study which was conducted in a highly heterogeneous environment for particle deposition. Second, the seasonal effect can affect particulate removal because of comprehensive effect of various factors like wind speed, rainfall, PM concentration and particle size distribution, humility and so on. In Guangzhou in China, the dust retention was higher in the dry season (Liu et al., 2013). Seasonal variation of dust retention also showed up in Beijing. Different species showed different dust retention responses to the season, some accumulated more particulate matter in spring whereas some accumulated more in the summer to autumn (Chen et al., 2017).

\section{Conclusion}

Fragstats was used in this study to calculate the metrics, including traditional indexes, such as size, shape, and spatial distribution in different diameter intervals, and to evaluate the characteristics of the leaf surface particles. Landscape metrics were modified to indicate the leaf particle characteristics.

Landscape ecology framework, exemplified in our study, can facilitate the understanding of leaf particles. Fragstats, a landscape analysis software, can be applied to examine leaf particles. Landscape metrics after transformation can also quantify the particles on plants in terms of comprehensive metrics, namely: size, shape, and spatial characteristics. The spatial concept was introduced and initially quantified in this particle deposition on leaf surface research.

Weight alone is insufficient to quantify the importance of vegetation on particle deposition because particle size distribution size should be considered. $S$. matsudana is an efficient species for particle accumulation in terms of quantity and quality. A. altissima performed better than Fraxinus chinensis Roxb did. Particles exhibit different shapes and sizes. In general, small particles have simple shapes and large particles usually have complex shapes. A new phenomenon was detected in this study. In particular, PM of different classes from various species show distinct proximity characteristics. Large particles have lower proximity than other classes. The $\mathrm{PM}_{10}$ have relatively higher proximity than other classes.

Our study may facilitate further research on the mechanism of particle retention by vegetation and the assessment and prediction of airborne particle deposition locally, regionally, and globally. The proposed technology can be used to identify the particles in situ and quantify the position between particles and specific leaf structures, such as the stoma. This technology may also be utilized to examine the effects of particles on leaves and plant physiology. 


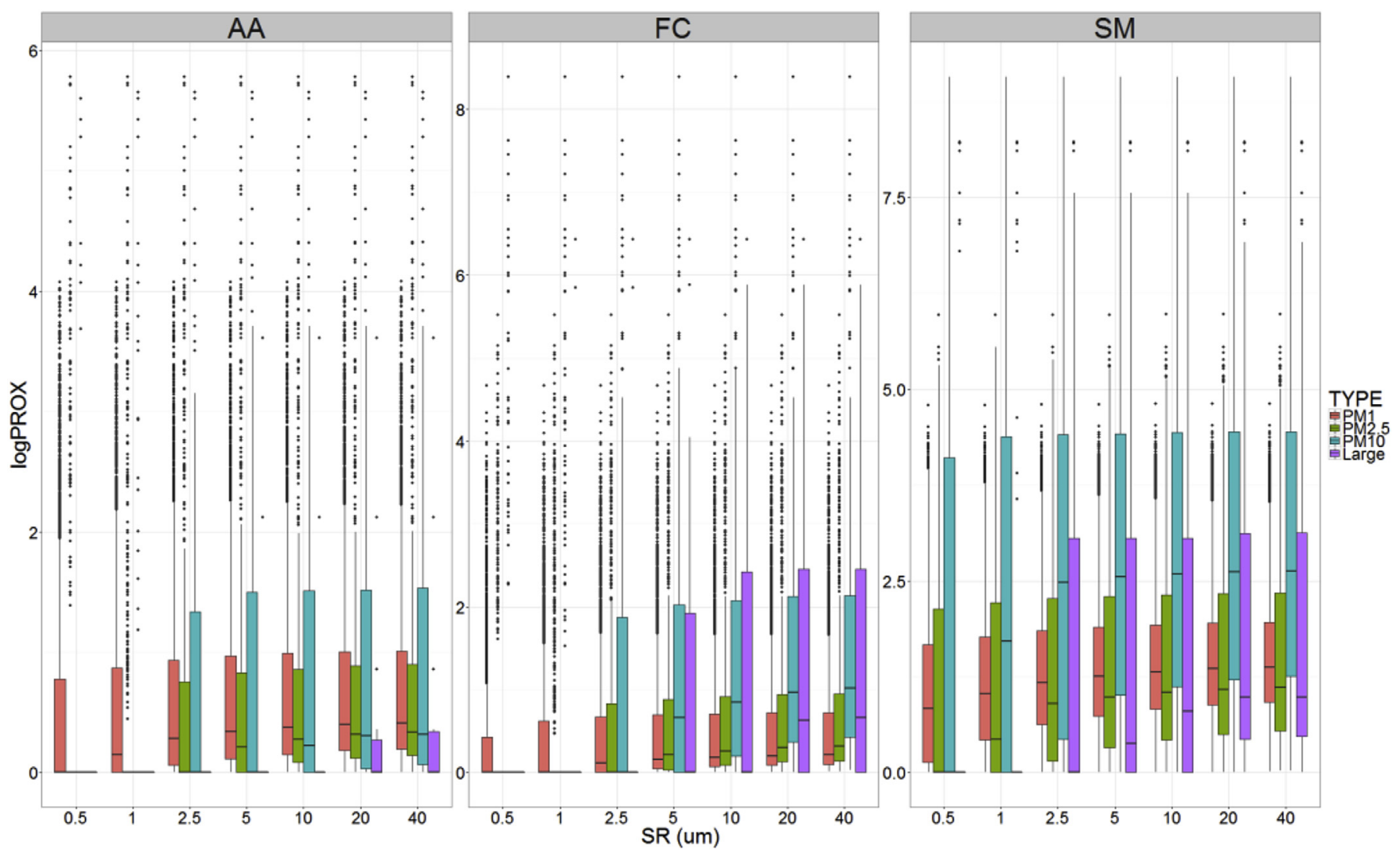

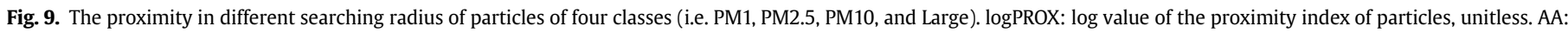
ailanthus (Ailanthus altissima (Mill.) Swingle); FC: ash (Fraxinus chinensis Roxb.); SM: willow (Salix matsudana Koidz.).

\section{Acknowledgements}

This research is supported by National Science Foundation of China (Key Program: No. 41430638), State Key Project (2016YFC0503003), the Innovation Project of the State Key Laboratory of Urban and Regional Ecology of China, National Science Foundation of China (31500381).

\section{References}

Abhijith, K.V., Kumar, P., Gallagher, J., McNabola, A., Baldauf, R., Pilla, F., Broderick, B., Di Sabatino, S., Pulvirenti, B., 2017. Air pollution abatement performances of green infrastructure in open road and built-up street canyon environments - a review. Atmos. Environ. 162, 71-86.

Akram, W., Madhuku, M., Ahmad, I., Li, X.L., Zhang, G.L., Yan, L., 2014. Morphology, microstructure and chemical composition of single inhalable particles in Shanghai, China, Environ. Monit. Assess. 186, 8587-8598.

Baldauf, R., Thoma, E., Khlystov, A., Isakov, V., Bowker, G., Long, T., Snow, R., 2008. Impacts of noise barriers on near-road air quality. Atmos. Environ. 42, $7502-7507$.

Baumgardner, D., Varela, S., Escobedo, F.J., Chacalo, A., Ochoa, C., 2012. The role of a peri-urban forest on air quality improvement in the Mexico City megalopolis. Environ. Pollut. 163, 174-183.

Beckett, K.P., Freer-Smith, P.H., Taylor, G., 1998. Urban woodlands: their role in reducing the effects of particulate pollution. Environ. Pollut. 99, 347-360.

Beckett, K.P., Freer-Smith, P., Taylor, G., 2000a. Particulate pollution capture by urban trees: effect of species and windspeed. Glob. Change Biol. 6, 995-1003.

Beckett, K.P., Freer Smith, P., Taylor, G., 2000b. Effective tree species for local air quality management. J. Arboric. 26, 12-19.

Bell, J.N.B., Honour, S.L., Power, S.A., 2011. Effects of vehicle exhaust emissions on urban wild plant species. Environ. Pollut. 159, 1984-1990.

Boys, B.L., Martin, R.V., van Donkelaar, A., MacDonell, R.J., Hsu, N.C., Cooper, M.J., Yantosca, R.M., Lu, Z., Streets, D.G., Zhang, Q., Wang, S.W., 2014. Fifteen-year global time series of satellite-derived fine particulate matter. Environ. Sci. Technol. 48, 11109-11118.

Buseck, P.R., Posfai, M., 1999. Airborne minerals and related aerosol particles: effects on climate and the environment. P Natl. Acad. Sci. U. S. A. 96, 3372-3379.
Cabaraban, M.T.I., Kroll, C.N., Hirabayashi, S., Nowak, D.J., 2013. Modeling of air pollutant removal by dry deposition to urban trees using a WRF/CMAQ/i-tree eco coupled system. Environ. Pollut. 176, 123-133.

Cao, C., Lee, X., Liu, S., Schultz, N., Xiao, W., Zhang, M., Zhao, L., 2016. Urban heat islands in China enhanced by haze pollution. Nat. Commun. 7, 12509.

Cao, Z.Z., Yang, Y.H., Lu, J.L., Zhang, C.X., 2011. Atmospheric particle characterization, distribution, and deposition in Xi'an, Shaanxi Province, Central China. Environ. Pollut. 159, 577-584.

Chen, L., Liu, C., Zhang, L., Zou, R., Zhang, Z., 2017. Variation in tree species ability to capture and retain airborne fine particulate matter (PM2.5). Sci. Rep. 7, 3206.

Deljanin, I.V., Tomasevic, M.N., Urosevic, M.P.A., Antanasijevic, D.Z., PericGrujic, A.A., Ristic, M.D., 2014. Lead isotopic composition in tree leaves as tracers of lead in an urban environment. Ecol. Indic. 45, 640-647.

Escobedo, F.J., Nowak, D.J., 2009. Spatial heterogeneity and air pollution removal by an urban forest. Landsc. Urban Plan. 90, 102-110.

Feng, Z.W., Huang, Y.Z., Feng, Y.W., Ogura, N., Zhang, F.Z., 2001. Chemical composition of precipitation in Beijing area, northern China. Water Air Soil Poll. 125 $345-356$.

Fowler, D., Pilegaard, K., Sutton, M.A., Ambus, P., Raivonen, M., Duyzer, J., Simpson, D., Fagerli, H., Fuzzi, S., Schjoerring, J.K., Granier, C., Neftel, A. Isaksen, I.S.A., Laj, P., Maione, M., Monks, P.S., Burkhardt, J., Daemmgen, U. Neirynck, J., Personne, E., Wichink-Kruit, R., Butterbach-Bahl, K., Flechard, C., Tuovinen, J.P., Coyle, M., Gerosa, G., Loubet, B., Altimir, N., Gruenhage, L., Ammann, C., Cieslik, S., Paoletti, E., Mikkelsen, T.N., Ro-Poulsen, H., Cellier, P., Cape, J.N., Horvath, L., Loreto, F., Niinemets, U., Palmer, P.I., Rinne, J., Misztal, P., Nemitz, E., Nilsson, D., Pryor, S., Gallagher, M.W., Vesala, T., Skiba, U., Brueggemann, N., Zechmeister-Boltenstern, S., Williams, J., O'Dowd, C. Facchini, M.C., de Leeuw, G., Flossman, A., Chaumerliac, N., Erisman, J.W., 2009. Atmospheric composition change: ecosystems-atmosphere interactions. Atmos. Environ. 43, 5193-5267.

Grantz, D., Garner, J., Johnson, D., 2003. Ecological effects of particulate matter Environ. Int. 29, 213-239.

Guo, S., Hu, M., Zamora, M.L., Peng, J.F., Shang, D.J., Zheng, J., Du, Z.F., Wu, Z., Shao, M., Zeng, L.M., Molina, M.J., Zhang, R.Y., 2014. Elucidating severe urban haze formation in China. P Natl. Acad. Sci. U. S. A. 111, 17373-17378.

Hijmans, R.J., 2015. Raster: Geographic Data Analysis and Modeling. R package version 2.3-33 ed.

Hirabayashi, S., Kroll, C.N., Nowak, D.J., 2012. Development of a distributed air pollutant dry deposition modeling framework. Environ. Pollut. 171, 9-17.

Hirabayashi, S., Nowak, D.J., 2016. Comprehensive national database of tree effects 
on air quality and human health in the United States. Environ. Pollut. 215, $48-57$.

Irga, P.J., Burchett, M.D., Torpy, F.R., 2015. Does urban forestry have a quantitative effect on ambient air quality in an urban environment? Atmos. Environ. 120, $173-181$.

Janhäll, S., 2015. Review on urban vegetation and particle air pollution - deposition and dispersion. Atmos. Environ. 105, 130-137.

Kampa, M., Castanas, E., 2008. Human health effects of air pollution. Environ. Pollut. $151,362-367$.

Karner, A.A., Eisinger, D.S., Niemeier, D.A., 2010. Near-roadway air quality: synthesizing the findings from real-world data. Environ. Sci. Technol. 44, 5334-5344.

Kelly, F.J., Fussell, J.C., 2012. Size, source and chemical composition as determinants of toxicity attributable to ambient particulate matter. Atmos. Environ. 60, 504-526.

Liang, D., Ma, C., Wang, Y.Q., Wang, Y.J., Zhao, C.X., 2016. Quantifying PM2.5 capture capability of greening trees based on leaf factors analyzing. Environ. Sci. Pollut. R. $1-11$.

Liu, L., Guan, D.S., Peart, M.R., Wang, G., Zhang, H., Li, Z.W., 2013. The dust retention capacities of urban vegetation-a case study of Guangzhou, South China. Environ. Sci. Pollut. R. 20, 6601-6610.

Madaniyazi, L., Nagashima, T., Guo, Y., Yu, W., Tong, S., 2015. Projecting fine particulate matter-related mortality in East China. Environ. Sci. Technol. 49 $11141-11150$.

Makkonen, U., Hellen, H., Anttila, P., Ferm, M., 2010. Size distribution and chemical composition of airborne particles in south-eastern Finland during different seasons and wildfire episodes in 2006. Sci. Total Environ. 408, 644-651.

Manisha, H., Pandian, E.S., Pal, A.K., 2016. Determining the contribution of nearby power plants to deposited foliar dust: a case study of BTPS, Bokaro. Arch. Environ. Con Tox 71, 485-499.

Martell, E.A., 1974. Radioactivity of tobacco trichomes and insoluble cigarette smoke particles. Nature 249, 215-217.

McGarigal, K., Cushman, S.A., Ene, E., 2012. FRAGSTATS V4: Spatial Pattern Analysis Program for Categorical and Continuous Maps. Computer software program produced by the authors at the University of Massachusetts, Amherst. Available at: the following web site: http://www.umass.edu/landeco/research/fragstats/ fragstats.html.

Nowak, D.J., 2006. Institutionalizing urban forestry as a "biotechnology" to improve environmental quality. Urban For Urban Gree 5, 93-100.

Nowak, D.J., Crane, D.E., Stevens, J.C., 2006. Air pollution removal by urban trees and shrubs in the United States. Urban For Urban Gree 4, 115-123.

Nowak, D.J., Hirabayashi, S., Bodine, A., Greenfield, E., 2014. Tree and forest effects on air quality and human health in the United States. Environ. Pollut. 193, 119-129.

Nowak, D.J., Hirabayashi, S., Bodine, A., Hoehn, R., 2013. Modeled PM2.5 removal by trees in ten US cities and associated health effects. Environ. Pollut. 178, $395-402$.

Oberdörster, G., 2000. Pulmonary effects of inhaled ultrafine particles. Int. Arch. Occ. Env. Hea 74, 1-8.

Pui, D.Y.H., Chen, S.C., Zuo, Z.L., 2014. PM2.5 in China: measurements, sources, visibility and health effects, and mitigation. Particuology 13, 1-26.

R Core Team, 2014. R: a Language and Environment for Statistical Computing. R Foundation for Statistical Computing, Vienna, Austria.

Räsänen, J.V., Holopainen, T., Joutsensaari, J., Ndam, C., Pasanen, P., Rinnan, Å., Kivimäenpää, M., 2013. Effects of species-specific leaf characteristics and reduced water availability on fine particle capture efficiency of trees. Environ. Pollut. 183, 64-70.

Rosenfeld, D., 2000. Suppression of rain and snow by urban and industrial air pollution. Science 287, 1793.

Sgrigna, G., Baldacchini, C., Esposito, R., Calandrelli, R., Tiwary, A., Calfapietra, C. 2016. Characterization of leaf-level particulate matter for an industrial city using electron microscopy and X-ray microanalysis. Sci. Total Environ. 548, 91-99.

Sierra-Vargas, M.P., Teran, L.M., 2012. Air pollution: impact and prevention. Respirology 17, 1031-1038.

Song, Y.S., Maher, B.A., Li, F., Wang, X.K., Sun, X., Zhang, H.X., 2015. Particulate matter deposited on leaf of five evergreen species in Beijing, China: source identification and size distribution. Atmos. Environ. 105, 53-60.

StoffynEgli, P., Potter, T.M., Leonard, J.D., Pocklington, R., 1997. The identification of black carbon particles with the analytical scanning electron microscope: methods and initial results. Sci. Total Environ. 198, 211-223.

Strak, M., Janssen, N.A.H., Godri, K.J., Gosens, I., Mudway, I.S., Cassee, F.R., Lebret, E., Kelly, F.J., Harrison, R.M., Brunekreef, B., Steenhof, M., Hoek, G., 2012. Respiratory health effects of airborne particulate matter: the role of particle size, composition, and oxidative potential-the RAPTES project. Environ. Health Persp 120, 1183-1189.

Sun, Y.L., Wang, Z.F., Du, W., Zhang, O., Wang, O.Q., Fu, P.O., Pan, X.L., Li, J., Jayne, J., Worsnop, D.R., 2015. Long-term real-time measurements of aerosol particle composition in Beijing, China: seasonal variations, meteorological effects, and source analysis. Atmos. Chem. Phys. 15, 10149-10165.

Tiwary, A. Sinnett, D. Peachey, C. Chalabi, Z. Vardoulakis, S., Fletcher, T. Leonardi, G., Grundy, C., Azapagic, A., Hutchings, T.R., 2009. An integrated tool to assess the role of new planting in PM10 capture and the human health benefits: a case study in London. Environ. Pollut. 157, 2645-2653.

Tong, Z., Baldauf, R.W., Isakov, V., Deshmukh, P., Max Zhang, K., 2016. Roadside vegetation barrier designs to mitigate near-road air pollution impacts. Sci. Total Environ. 541, 920-927.

van Donkelaar, A., Martin, R.V., Brauer, M., Boys, B.L., 2015. Use of satellite observations for long-term exposure assessment of global concentrations of fine particulate matter. Environ. Health Perspect. 123, 135-143.

Wang, Y., Zhang, R., Saravanan, R., 2014. Asian pollution climatically modulates midlatitude cyclones following hierarchical modelling and observational analysis. Nat. Commun. 5, 3098.

Wickham, H., 2009. ggplot2: Elegant Graphics for Data Analysis. Springer-Verlag, New York.

Xie, R., Sabel, C.E., Lu, X., Zhu, W., Kan, H., Nielsen, C.P., Wang, H., 2016. Long-term trend and spatial pattern of PM2.5 induced premature mortality in China. Environ. Int. 97, 180-186.

Yan, J., Lin, L., Zhou, W., Han, L., Ma, K., 2016a. Quantifying the characteristics of particulate matters captured by urban plants using an automatic approach. J. Environ. Sci-China 39, 259-267.

Yan, J., Lin, L., Zhou, W., Ma, K., Pickett, S.T.A., 2016b. A novel approach for quantifying particulate matter distribution on leaf surface by combining SEM and object-based image analysis. Remote Sens. Environ. 173, 156-161.

Yan, X., Shi, W.Z., Zhao, W.J., Luo, N.N., 2015. Mapping dustfall distribution in urban areas using remote sensing and ground spectral data. Sci. Total Environ. 506, 604-612.

Yu, Q., Gong, P., Clinton, N., Biging, G., Kelly, M., Schirokauer, D., 2006. Object-based detailed vegetation classification with airborne high spatial resolution remote sensing imagery. Photogrammetric Eng. Remote Sens. 72, 799-811.

Zampieri, M.C.T., Sarkis, J.E.S., Pestana, R.C.B., Tavares, A.R., Melo-de-Pinna, G.F.A., 2013. Characterization of Tibouchina granulosa (Desr.) Cong. (Melastomataceae) as a biomonitor of air pollution and quantification of particulate matter adsorbed by leaves. Ecol. Eng. 61, 316-327.

Zhang, L., He, Z., 2014. Technical note: an empirical algorithm estimating dry deposition velocity of fine, coarse and giant particles. Atmos. Chem. Phys. 14, 3729-3737.

Zhang, X.Y., Wang, Y.Q., Niu, T., Zhang, X.C., Gong, S.L., Zhang, Y.M., Sun, J.Y., 2012. Atmospheric aerosol compositions in China: spatial/temporal variability, chemical signature, regional haze distribution and comparisons with global aerosols. Atmos. Chem. Phys. 12, 779-799. 